
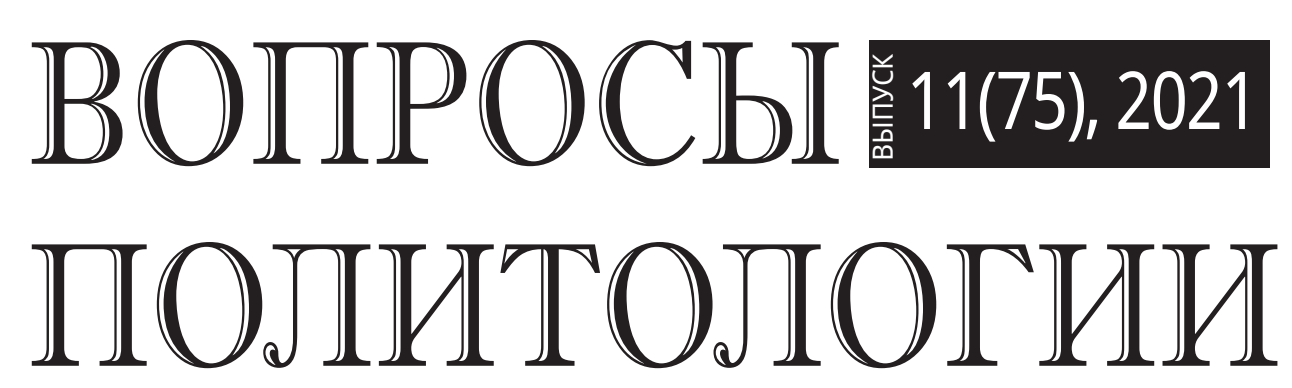

Научный журнал

Журнал «Вопросы политологии» включен

в Перечень рецензируемых научных изданий

ВАК при Министерстве науки и высшего образования РФ

по политическим наукам, в которых должны быть опубликованы основные научные результаты на соискание ученой степени кандидата наук, на соискание ученой степени доктора наук

Журнал включен в Перечень научных изданий рекомендованных ВАК Республики Узбекистан для публикации основных научных результатов диссертаций по политическим и философским наукам 
Председатель Редакционного Совета - ПЛАТОНОВ В.М.,

к.ю.н., заведующий кафедрой политического анализа и управления РУДН,

Председатель Московской городской Думы (1994-2014 гг.)

\section{Редакционный Совет}

АВАЗОВ

Камиль Халлиевич

\section{АСТВАЦАТУРОВА}

Майя Арташесовна

БЛОХИН

Владимир Владимирович

БОЖАНОВ

ВАНКОВСКА

Биляна

\section{ВЕДРИН}

Оливье

Наталия Михайловна

ГОНЧАРОВ

Пётр Константинович

ГРАЧЁВ

Михаил Николаевич

ДЭМБЭРЭЛ К.

ДОНАЙ

Лукаш

ЖИЛЬЦОВ

Сергей Сергеевич

КАРАДЖЕ

Татьяна Васильевна

КАССАЕ НЫГУСИЕ

В. МИКАЭЛЬ

КОВАЛЕНКО

Валерий Иванович

КОМЛЕВА

Валентина Вячеславовна

КРИВОКАПИЧ

Борис

МЕДВЕДЕВ

Николай Павлович

МИХАЙЛОВ

Вячеслав Александрович

НАЗАРОВА

Елена Александровна

НАЗАРОВ

Александр Данилович

НАСИМОВА

Гульнара Орленбаевна

НИСНЕВИЧ

Юлий Анатольевич

ОРЛОВ

Игорь Борисович

ПАХРУТДИНОВ

Шукритдин Ильясович

ПЛЯЙС

Яков Андреевич

ПРЯХИН

Владимир Федорович

ПУСЬКО

Виталий Станиславович

СЛИЗОВСКИЙ

Дмитрий Егорович

СЫЗДЫКОВА

Жибек Сапарбековна

ХОПЁРСКАЯ

Лариса Львовна

ШАРКОВ

Феликс Изосимович

ЯН ФУЛИНЬ
Владимир Александрович

ВЕЛИКАЯ

д.ф. (PhD) по полит. наукам, Региональный центр переподготовки и повышения квалификации работников народного образования Сурхандарьинской области (Узбекистан, г. Ташкент) д.П.н., профессор, Пятигорский государственный университет (Россия, г. Пятигорск) д.и.н., профессор, РУДН (Россия, г. Москва)

д.и.н., профессор, Белорусский Национальный технический университет (Белоруссия, г. Минск)

профессор политологии и международных отношений

факультета философии Университета Святых Кирилла и Мефодия

(Македония, г. Скопье)

профессор, ректор «Континентального университета в Киеве»

(Франция, г. Париж)

д.п.н., профессор, ИСПИ ФНИСЦ РАН, РГГУ (Россия, г. Москва)

д.с.н., профессор, Российский университет транспорта (МИИТ)

(Россия, г. Москва)

д.П.н., профессор, РГГУ (Россия, г. Москва)

доктор (PhD), Институт международных отношений АН Монголии (Монголия, г. Улан-Батор)

д.п.н., профессор, Университет им. Адама Мицкевича в Познани (Польша, г. Познань)

д.П.н., профессор, Дипломатическая академия МИД РФ

(Россия, г. Москва)

д.ф.н., профессор, МПГУ (Россия, г. Москва)

д.и.н., профессор, РУДН (Россия, г. Москва)

д.ф.н., профессор, МГУ им. М.В. Ломоносова (Россия, г. Москва)

д.с.н., профессор, РАНХиГС при Президенте РФ (Россия, г. Москва)

д.ю.н., Унион-Никола Тесла университет (Сербия, г. Белград)

д.п.н., профессор, главный редактор журнала (Россия, г. Москва)

д.и.н., профессор, РАНХиГС при Президенте РФ (Россия, г. Москва)

д.с.н., профессор, МГИМО МИД России (Россия, г. Москва)

д.и.н., профессор, МАИ (Россия, г. Москва)

д.п.н., профессор, Казахский Национальный университет

им. Аль-Фараби (Казахстан, г. Алматы)

д.п.н., профессор, НИУ «Высшая школа экономики»

(Россия, г. Москва)

д.и.н., профессор, НИУ «Высшая школа экономики»

(Россия, г. Москва)

д.п.н., профессор, Институт переподготовки и повышения

квалификации руководителей и специалистов системы народного

образования имени А. Авлони (Узбекистан, г. Ташкент)

д.и.н., Д.П.н., профессор, Финансовый университет при Правительстве РФ (Россия, г. Москва)

д.п.н., профессор, РГГУ (Россия, г. Москва)

д.ф.н., профессор, ВА РВСН им. Петра Великого (Россия, г. Москва)

д.и.н., профессор, РУДН (Россия, г. Москва)

д.и.н., профессор, ИСАА МГУ им. М.В. Ломоносова

(Россия, г. Москва)

д.П.н., профессор, Киргизско-Российский славянский университет

(Киргизия, г. Бишкек)

д.с.Н., профессор, РАНХиГС при Президенте РФ (Россия, г. Москва)

проректор Хэйлунцзянского института иностранных языков (КНР, г. Харбин)

\section{Редакционная коллегия}

Главный редактор - МЕДВЕДЕВ Н.П., д.П.Н., профессор

Абрамова О.Д. (д.П.н.)

Насимова Г.О. (д.п.н.)

Кетцян Г.В. (к.П.н. - зам. гл. редактора)
Шкурина С.С. (к.П.н. - ответ. редактор)

\section{ЖУРНАЛ ВКЛЮЧЕН В ПЕРЕЧЕНЬ ВАК РФ}

\author{
УЧРЕЖДЕН \\ ООО «Издательство \\ «Наука сегодня»
}

Журнал зарегистрирован

Федеральной службой

по надзору в сфере массовых коммуникаций, связи и охраны культурного наследия

Рег. № ПИ № ФС77-46176 от 12 августа 2011 г.

Журнал издается ежемесячно

Журнал включен в базу РИНЦ

(Российский индекс

научного цитирования)

Включен в каталог

Ulrich's Periodicals Directory

Пятилетний импакт-фактор: 1,489.

Адрес редакции:

115598 , г. Москва, ул. Загорьевская, д. 10, корп. 4, цокольный этаж, помещение I, комната 7-1, офис 4

Тел.: (910) 463-53-42

Интернет-ресурс:

www.voprospolitolog.ru

E-mail: voprospolitolog@yandex.ru

Мнение авторов может не совпадать с мнением редакции.

При перепечатке ссылка

на журнал обязательна.

Научные статьи, публикуемые в журнале подлежат обязательному рецензированию.

Ответственный редактор Шкурина С.C.

Перевод

Чернышова Е.B.

Компьютерная верстка Анциферова А.С.

Подписано в печать 25.11.2021

Формат 60×84/8. Объем 24,3 Печать офсетная Тираж - 1000 эКз.

(1-й завод - 500 экз.) Заказ № 000.

Отпечатано в типографии OOO «Белый ветер»

115054, г. Москва, ул. Щипок, 28 Тел.: (495) 651-84-56 
ISSN 2225-8922 (print)

12 выпусков в год и

4 выпуска в год переводной (англ.) версии

Языки: русский, английский

http://voprospolitolog

Входит в перечень рецензируемых научных изданий ВАК РФ Включен в каталог периодических изданий Ульрих

(Ulrich's Periodicals Directory: http://www.ulrichsweb.com)

Материалы журнала размещаются на платформе РИНЦ

Российской научной электронной библиотеки, Electronic Journals Library Cyberleninka

Подписной индекс издания в каталоге агентства Роспечать 70035

\section{Цели и тематика}

Журнал ВОПРОСЫ ПОЛИТОЛОГИИ - периодическое международное рецензируемое научное издание в области политических исследований. Журнал является международным как по составу редакционного совета и редколлегии, так и по авторам и тематике публикаций.

Научный журнал издается с 2011 года в издательстве «Наука сегодня». С 2016 года издается переводная (англ.) версия журнала. С момента своего создания, журнал ориентировался на высокие научные и этические стандарта и сегодня является одним из ведущих политологических журналов России.

Цель журнала - способствовать научному обмену и сотрудничеству между российскими и зарубежными политологами.

Журнал предназначен для публикации результатов фундаментальных и прикладных научных исследований. Тематическая направленность журнала отражается в следующих постоянных рубриках: «История и философия политики», «Политические институты, процессы и технологии», «Политическая регионалистика и этнополитика», «Политическая культура и идеологии», «Политические проблемы международных отношений и глобализации».

Формат публикаций: научные статьи, обзорные научные материалы, материалы круглых столов, научные рецензии, научные сообщения, посвященные исследовательским проблемам в сфере политики и политологии.

В своей деятельности редакционный совет и редколлегия журнала руководствуется принципами, определяемыми ВАК России для научных журналов, в том числе: наличие института рецензирования для экспертной оценки качества научных статей; информационная открытость издания; наличие и соблюдение правил и этических стандартов представления рукописей авторами.

Целевой аудиторией журнала являются российские и зарубежные специалисты-политологи, а также аспиранты и магистры, обучающиеся по направлениям политология, государственное и муниципальное управление и международные отношения.

Журнал строго придерживается международных стандартов публикационной этики, обозначенных в документе СОРЕ (Committee on Publication Ethics) http://publicationethics.org

Полные сведения о журнале и его редакционной политике, требования о подготовке и публикации статей, архив (выпуски c 2011 года) и дополнительная информация размещена на сайте: http://voprospolitolog.ru

Электронный адрес: voprospolitolog@yandex.ru

ISSN 2225-8922 (print)

12 issues a year plus 4 issues a year of the translated (eng.) version Languages: Russian and English http://voprospolitolog

Included in the list of peer-reviewed scientific publications of the Higher Attestation Commission of the Russian Federation Included in the Ulrich's Periodicals Directory Materials of the journal are placed on the RSCI platform of the Russian scientific electronic library - Electronic Journals Library Cyberleninka Subscription index of the journal in the Rospechat Agency catalogue is: 70035

\section{Objectives and themes}

Academic journal "Political Science Issues" is an international peer-reviewed scientific periodical in the field of political studies. The journal has an international character because of the composition of its Editorial Board, its editors, its contributing authors and topics of its publications.

The scientific journal is published since 2011 at the "Publishing House "Science Today". Translated (eng.) version of the journal is published since 2016. Since its inception, the journal was guided by high scientific and ethical standards and today it is one of the leading political science journals in Russia.

The purpose of the journal is to promote scientific exchange and cooperation between Russian and foreign political scientists.

The journal is intended for the publication of the results of fundamental and applied scientific research. Thematic focus of the journal is reflected in the following permanent headings: "History and philosophy of politics," "Political institutions, processes and technologies," "Political regionalism and ethno-politics," "Political culture and ideologies," "Political problems of international relations and globalization."

Format of publications: scientific articles, reviews, scientific materials, materials of round tables, scientific reviews, scientific reports devoted to research problems in the field of politics and political science.

The Editorial Board and the editors of the journal in their activities are guided by the principles defined by VAK of Russia for scientific journals, including: presence of the institute of peer review for the expert quality assessment of scientific articles; information openness of the publications; availability and compliance with the rules and ethical standards for the submission of manuscripts by the authors.

The target audience of the journal is Russian and foreign specialists-political scientists, as well as graduate students and masters in the fields of political science, state and municipal management and international relations.

The journal strictly adheres to the international publishing standards and publication ethics identified in the COPE (Committee on Publication Ethics) document. http://publicationethics.org.

Full details of the journal and its editorial policy, requirements to the preparation and publication of articles, archive (issues since 2011) and additional information are available on the website: http://voprospolitolog.ru

E-mail address: voprospolitolog@yandex.ru 


\section{ИСТОРИЯ И ТЕОРИЯ ПОЛИТИКИ}

Гончаров П.К. Современная политическая культура:

к определению понятия 3008

Солодова Г.С. Поиск универсальных закономерностей критический взгляд Р. Будона на теории социальных изменений. 3014

Берёзкина E. Ю. Вариации интерпретации популизма

в современной политологии..... 3020

\section{ПОЛИТИЧЕСКАЯ ИСТОРИЯ РОССИИ}

Гаджиев М.M. Драматическая эволюция государственно-конфессиональных отношений в Республике Дагестан в постсоветский период: от религиозно-политической конфронтации до региональной стабилизации 3028

Наледин И.И. Политические партии

Крымского полуострова и их влияние на избирательную систему Крыма в постсоветский период

\section{ПОЛИТИЧЕСКАЯ СОЦИОЛОГИЯ}

Абрамова М.А. Применение социокультурного

и интеракционисткого подходов в изучении трансформаций социокультурного пространства

Макаренко К.М., Панкратов С.А., Панкратова Л.С.

Трансформация гражданского протеста в современной России:

выбор форм онлайн и офлайн активности.

Цуприк М.И. К вопросу об исследовании

инструментария изучения политической идентичности.

\section{ПОЛИТИЧЕСКИЕ ИНСТИТУТЫ, ПРОЦЕССЫ И ТЕХНОЛОГИИ}

Володина Н.А., Ретинская В.Н. Особенности реализации российской государственной антикоррупционной политики в условиях информационного общества и электронного государства.

Андреева Ю.В., Липатова A.B. Факторы влияния политических традиций на технологии конструирования медиаобраза регионального лидера.

Калиев И.А., Алтыбасарова М.А. Информационные технологии в политическом процессе: политологический анализ ....

Прончев Г.Б., Михайлов А.П. Виртуальные социальные среды интернета как инструмент политической борьбы

Алексеев Р.А., Еж⿻в Д.А., Шакурова Н.Е. Практика организации электронных референдумов в России: особенности апробации .

Добрынина М.В., Огородов Д.А. Формирование советской политики в области физкультуры, спорта и спортивного образования: идеологические основания 
Мадюкова $\boldsymbol{C}$. . Н. Национальная политика

в социокультурном пространстве региона

(на примере Республики Алтай).

Николенко $\boldsymbol{A}$. $A$. Легитимация властных структур и ее особенности

в рамках концепции «русской локальной цивилизации»

Ocunoв A.B. Социально-политический мониторинг

и социально-медийная предиктивная аналитика как инструменты

и технологии консолидации политической власти

Сабирова H.C. Влияние средств массовой информации

на политическую культуру современной России

Лапшина Д.М., Попов С.И. Кадровая политика государственной

гражданской службы России на современном этапе

и пути ее совершенствования

Калиниченко A.O. Российский федерализм

в развилке конституционной реформы

Файзиев 3. Влияние религиозной толерантности

на межнациональные отношения

Лебедева $\boldsymbol{E}$. $\boldsymbol{A}$. Снижение проходного барьера

и наличие графы «против всех» как показатели

демократичности выборов в современной России

Малахов А.А. Концепция всеобщего благосостояния

и ее реализация в целях и функциях государства

Романова Ю.А. Развитие научно-технической

инновационной инфраструктуры субъектов Российской Федерации,

входящих в состав ЦФО

Салимов Д.М. Политическая цензура

и сетевые СМИ в современном Таджикистане

\section{ГОСУДАРСТВЕННОЕ УПРАВЛЕНИЕ И ОТРАСЛЕВЫЕ ПОЛИТИКИ}

Жолманов А.С., Афонин М.В., Кривова А.Л. Коррупционные риски

как категория антикоррупционной политики.

ТЕОРИЯ И ИСТОРИЯ МЕЖДУНАРОДНЫХ ОТНОШЕНИЙ И ВНЕШНЕЙ ПОЛИТИКИ

Абрамов В.Л., Прокофьев В.А. Устойчивые конкурентные

преимущества стран в контексте эволюции теоретических подходов

по развитию мировой торговли

Юрасов И.А., Володина Н.А. Историческая память

российской молодежи как основа формирования

государственно-ориентированной личности

Тушков А.А., Животова Д.А. Вестернизация Японии

как импрувер культурного кроссинговера 
Чемшит А.А., Ковалевский А.А. Глобальные

и европейские противоречия в современном

геополитическом дискурсе в Болгарии (Часть II)

Воронина H.A. Механизмы транснациональной коммуникации

в сфере миграции в современную эпоху.....

Агоннуде Бидолей Вианней Фредди. Приоритеты ЮАР в G20 .

Хабаров И.А. Маршруты символического

конструирования пространства:

от составления карты к штурму горизонтов

Чучин М.И., Адутов Р.P. Система поддержки принятия

решений в деятельности различных организаций

Иванченко М.A. Развитие политической системы

Аргентины в 30-40 годы ХХ века

Баракат Kaйс A.M. Внешняя политика США по отношению

к арабо-израильскому конфликту на современном этапе.

Казарян С.A., Бозоян T.P. Корпоративная социальная деятельность

транснациональных корпораций Соединенных Штатов Америки

в странах Юго-Восточной Азии

Власов A.B. Современные технологии публичной дипломатии

$\boldsymbol{E} \boldsymbol{\varepsilon}$

для контроля за деятельностью мировых ТНК

Золотарев H.A. Зарубежный опыт интеграции мигрантов:

практика современной Германии.

Клюкин Н.Д. Цифровая дипломатия в эпоху больших данных

Лебедева Е.И., Присекин А.А. Современное политическое

лидерство в Европе в контексте религиозного ренессанса

Петросян Ф.A. Политическая активность в шведском Риксдаге

сторонников и противников присоединения к НАТО

Симонова А.И. Анализ государственной политики Китая в области молодежных браков

Фаздалова Р. Политическая значимость Казани

в развитии китайско-российских отношений

Дуань Жань. Взаимодействие КНР со странами Центральной Азии

в области безопасности в рамках ШОС

Нина Рамос Росио Леонор. Внешнеполитический

вектор Бразилии в условиях становления нового мирового порядка

Добромыслов А.С. Политические аспекты глобального старения

\section{СТУДЕНЧЕСКАЯ НАУКА}

Лю Лу. США и Россия на пороге новой холодной войны. 
УДК 32.323

Д.М. ЛАПШИНА

магистрант кафедры государственного и муниципального управления Российского университета дружбы народов (RUDN University),

Россия, г. Москва

С.И. ПОПОВ

кандидат политических наук, дочент кафедры политического анализа и управления Российского университета дружбы народов (RUDN University), Россия, г. Москва

\section{КАДРОВАЯ ПОЛИТИКА ГОСУДАРСТВЕННОЙ ГРАЖДАНСКОЙ СЛУЖБЫ РОССИИ НА СОВРЕМЕННОМ ЭТАПЕ И ПУТИ ЕЕ СОВЕРШЕНСТВОВАНИЯ}

В статье рассматриваются ключевые вопросы кадровой политики в области государственной и муниципальной службы на современном этапе, проводится переосмысление подходов к отбору персонала в связи с появлением в Конститучии Российской Федерачии понятия «публичная власть», выявляются пробелы и недостатки существующей системы комплектования сотрудниками органов власти, предлагаются пути их устранения.

Ключевые слова: кадровая политика, государственная служба, мунициипальная служба, государственное управление, муниципальное управление, публичная власть, профессионализм, эффективность.

Изучение трудовых отношений на государственном и муниципальном уровнях власти, как правило, базируется на постулате о том, что организационные формы трудовых отношений на уровне отдельного государства или муниципалитета характеризуются свободным коллективным поиском оптимального решения управленческой задачи.

В работе академика РАЕН Прокофьева С.Е. «Государственная и муниципальная служба» справедливо отмечается, что «Государство приобретает реальность и силу именно в кадрах, в контингенте его служащих» [5. С. 115].

Подготовка кадрового персонала - это, прежде всего, развитие профессиональных знаний, умений и навыков сотрудников, исходя из целей развития соответствующих подразделений, которые в свою очередь привязаны к стратегии органов государственной власти. Подготовка кадрового персо- 
нала для органов государственной власти может быть разной по форме, содержанию и способу организации. Все это зависит от конкретных целей, временных и финансовых ресурсов.

Представляя собой определенный механизм реализации государственной кадровой политики, кадровая работа на государственной службе призвана обеспечить среду, в которой в полной мере используется кадровый потенциал, с сопутствующим развитием личных и профессиональны качеств государственных служащих.

В этой связи подбор, и расстановка кадров в системе государственного управления выступают достаточно важными категориями, а формирование кадровой политики приобретает общественное значение. От того, какое впечатление складывается у граждан о взаимодействии с государственными и муниципальными служащими, зависит мнение населения о действиях власти в целом, а это в конечном итоге влияет на процессы социальной и политической стабильности в государстве. Об этом речь идет уже не первый год, например, один из авторов этой статьи поднимал указанный вопрос еще в 2018 году [1. С. 737], однако в реальной практике на сегодняшний день так ничего и не изменилось.

Для обеспечения занятости в органах публичного государственного управления необходимо разработать систему подбора государственных служащих посредством специальных инструментов для установления пригодности соискателей и в отборе наиболее подходящих и перспективных кадров для государственной службы.

В процессе кадрового обеспечения государственной службы ответственными должностными лицами организовывают конкурс для замещения освободившихся вакантных мест. Одновременно с этим, наряду с анализом уровня и направления образования конкурсанта, профессионализма, опыта, сферы деятельности предыдущего места работы и других признаков, главным фактором становится оценка индивидуальных характеристик и отношений к окружающим. Основная цель - проанализировать относительно стабильные свойства личности потенциального государственного служащего.

Методы оценки государственных служащих зависит в первую очередь от характера и специфики их работы и как правило, оцениваются при помощи непосредственного собеседования и личной беседы с соискателем, а также при помощи тестирования.

В свою очередь, структура и формулировки вопросников при тестировании должны быть основаны на перечне основных качеств, требуемых от работника на определенную должность и положение. Такой список может быть составлен экспертным методом при помощи специалистов в области социологии, психологии и трудовых отношений.

Следует отметить, что в последнее время перечень специальностей персонала для органов государственной власти значительно расширил- 
ся, а система подготовки персонала для них - соответствующим образом не изменилась.

В целях улучшения практики подбора кадров государственной службы на должности целесообразно активно использовать проведение конкурсов. В противовес объективному конкурсу мы видим такой феномен как кадровый резерв, при чем требования для зачисления в него крайне занижены, а значит именно он может стать площадкой для некомпетентных кадров, полагаем, что человек зачисленный в кадровый резерв должен проходить также ряд процедур, определяющих его компетенцию повторно, не взирая на то что он находится в кадровом резерве. Это усилит кадровый потенциал, повысит качество принимаемых специалистов, активизирует подбор сотрудников через кадровые агентства, тем более, что органы публичного управления наделены определенными полномочиями по воздействию на процессы вопросов кадровой политики, а также регулированию рынка труда [4. С. 13].

Подводя промежуточный итог вышеизложенного, можно еще раз подчеркнуть основные конкретные проблемы, существующие в системе кадрового обеспечения государственного и муниципального управления:

- несоответствие профессионального образования и замещаемых должностей государственной службы;

- отсутствие профессий по информатизации управления;

- неидеальная схема подготовки и улучшения опыта государственных кадров: от старых учебных проектов, краткосрочных курсов обучения, до неимения курсов подготовки кадров вообще;

- ограничение государственного заказа организаций для обучения, а также числа сотрудников, которые будут обучаться в точно определенный срок.

Рассматривая эффективность проведения оценки кадрового персонала органов государственной власти, нужно учитывать несколько критериев оценки:

1. Систематичность проведения оценивания кадрового персонала органов государственной власти.

2. Четкость и ясность целей проведения оценки кадрового персонала органов государственной власти.

3. Прозрачность и понятность системы оценивания для персонала.

Успешность подбора направления деятельности государственного служащего обуславливают индивидуально-психические качества. Тип реализуемой профессиональной деятельности в международной практике обучения специалистов для органов государственной власти обязан соответствовать с индивидуальным, характерологическим видом индивида. К примеру, если человек общителен, ему более подходят профессии, связанные с множественными контактами; а в случае если человек эмоционально 
неустойчив, он не сможет осуществлять рутинную работу, призывающую к концентрации в течение продолжительного периода.

Кроме того, проникновение новых информационных технологий во все сферы общественной жизни привелои к изменению характера политического и, прежде всего, государственного управления [2. С. 49].

Необходимость в реформирования государственной службы вновь появилась в связи с тем, что формирование эффективной кадровой системы является важнейшей задачей текущего этапа трансформации власти.

Как известно, в соответствии с принятием 01 июля 2020 года поправок в Конституцию Российской Федерации органы местного самоуправления и органы государственной власти входят в единую систему публичной власти [3], что позволяет унифицировать, в том числе, требования к государственным и муниципальным служащим.

Профессионализм публичной службы - это уровень развития целей служащих, их мотивация и личные заслуги, который можно смело прировнять к уровню самой публичной службы. Сейчас на публичную службу вправе поступать граждане Российской Федерации, достигшие возраста 18 лет, владеющие государственным языком Российской Федерации и отвечающие квалификационным требованиям, установленным законодательством о гражданской службе. Это довольно широкий круг лиц, поэтому оценить профессиональные качества отдельно взятого кандидата может только профессиональный отбор и непосредственно служебная деятельность, например, под контролем опытного наставника.

Таким образом, кадровая политика в органах федеральной власти и муниципального управления становиться оторванной от действительности. Современный этап реформирования службы в публичных органах власти характеризует потребность в совершенствовании регулирования кадровой составляющей.

К сожалению, в проекте нового федерального Закона «Об общих принципах организации публичной власти в субъектах Российской Федерации» (законопроект № 1256381-7), рассмотренного Государственной Думой Федерального Собрания Российской Федерации 09.11.21 г. в первом чтении, ни слова не говорится о столь важном и значимом аспекте деятельности, как кадровая политика.

Будем надеяться, что со временем по этому поводу появится специальный закон, учитывающий мнение научного экспертного сообщества.

\section{БИБЛИОГРАФИЧЕСКИЙ СПИСОК:}

1. Александрова В.Ю., Попов С.И., Гусарская Т.А. Политика совершенствования системы аттестации государственных гражданских служащих // Вопросы политологии. 2018. Т. 8. № 10 (38). 
2. Анохин М.Г., Бочанов М.А., Ваховский А.М., Глебов В.А., Гришин О.Е., Давыцов В.Н., Матвеенков Д.О., Молодчая Н.Н. Политика. XXI век. Инновационные технологии / под общей редакцией М.Г. Анохина, В.М. Платонова, О.Е. Гришина. М., 2013.

3. Конституция Российской Федерации (принята на всенародном голосовании 12 декабря 1993 года) // (с учетом поправок, внесенных Законами Российской Федерации о поправках к Конституции Российской Федерации от 01.07.2020 г. № 11-ФКЗ) // http://www.consultant.ru/document/cons_doc_ LAW_28399/.

4. Ноженко Д.Ю. Государственные программы как инструмент стратегического управления: межрегиональный анализ // Вопросы управления. 2016. № 4 (22).

5. Прокофьев С.Е., Еремин С.Г. Государственная и муниципальная служба. М.: Юрайт, 2017.

\author{
D.M. LAPSHINA \\ Master of the Department of Public and \\ Municipal Administration, Peoples' Friendship University \\ of Russia, RUDN University, \\ Moscow, Russia \\ S.I. POPOV \\ Ph.D. in Political Science, Associate Professor, \\ Department of Policy Analysis and Management, \\ Peoples' Friendship University of Russia, \\ RUDN University, Moscow, Russia
}

\title{
PERSONNEL POLICY OF THE STATE CIVIL SERVICE OF RUSSIA AT THE PRESENT STAGE AND WAYS TO IMPROVE IT
}

The article examines the key issues of personnel policy in the field of state and municipal service at the present stage, rethinks approaches to personnel selection in connection with the appearance of the concept of "public authority" in the Constitution of the Russian Federation, identifies gaps and shortcomings of the existing system of recruitment of employees of authorities, suggests ways to eliminate them.

Key words: personnel policy, public service, municipal service, public administration, municipal administration, public authority, professionalism, efficiency. 